\title{
Possible Prophylactic Effect of Poria Mushroom Extract on Chemically-Induced Chronic Kidney Disease In Vitro and In Vivo
}

\author{
Jonathan Wagmaister ${ }^{1}$, Kelvin Zheng ${ }^{2}$, Muhammad Choudhury ${ }^{3}$, Majid Eshghi ${ }^{4}$, Sensuke Konno ${ }^{* 5}$ \\ ${ }^{1}$ Endourology Fellow, Department of Urology, New York Medical College, Valhalla 10595, USA \\ ${ }^{2}$ Medical Student, New York Medical College, Valhalla 10595, USA \\ ${ }^{3}$ Professor and Chairman, Department of Urology, New York Medical College, Valhalla 10595, USA \\ ${ }^{4}$ Professor, Department of Urology, New York Medical College, Valhalla 10595, USA \\ ${ }^{5}$ Associate Professor, Department of Urology, New York Medical College, Valhalla 10595, USA
}

"Corresponding author: Sensuke Konno, Ph.D., Department of Urology, New York Medical College, BSB Room A03, Valhalla, NY 10595, USA. E-mail: sensuke_konno@nymc.edu, Tel: 914-594-3745, Fax: 914-594-4428

Received 26 August 2019;

Accepted 15 September 2019;

Published 22 October 2019

\begin{abstract}
Background: Hypothesizing that oxidative stress (OXS) could be a key pathogenic factor for the incidence of chronic kidney disease (CKD), we investigated if the Poria mushroom extract, PE, with possible antioxidant activity, would prevent the incidence of CKD in rats. Materials and Methods: Antioxidant activity of PE was examined against OXS induced by hydrogen peroxide $\left(\mathrm{H}_{2} \mathrm{O}_{2}\right)$ in renal LLC-PK1 cells. Whether PE could prevent the development of CKD in the rat kidneys, mediated through adenine (ADN)-induced OXS, was also examined. After 2 weeks, blood and kidney specimens were collected from rats for blood, histopathologic, and biochemical analyses. $\underline{\text { Results: }}$ Although $\mathrm{H}_{2} \mathrm{O}_{2}$-induced OXS led to a significant cell viability reduction in LLC-PK1 cells, PE significantly diminished OXS and sustained high ( 70\%) cell viability. In rats, ADN-given rats showed typical renal dysfunction with palpable kidney damage; however, PE supplement improved renal function with better histology. A 2.2-fold increased OXS level was also seen in ADN-given rats but it was reduced by 27\% with PE supplement. Moreover, analysis of kidney injury biomarkers further confirmed extended kidney damage by ADN. Nevertheless, PE effectively maintained the natural status of those markers, protecting the rat kidneys. Conclusions: OXS is indeed harmful to renal cells in vitro and could even lead to ADNinduced CKD in vivo. However, PE appears to have antioxidant activity capable of protecting renal cells and the rat kidneys from such detrimental OXS. Therefore, it is rather possible that PE could be a natural antioxidant with prophylactic effect against OXS-induced CKD.
\end{abstract}

Keywords: Oxidative stress, chronic kidney disease, antioxidant, Poria mushroom.

\section{Introduction}

Among various kidney diseases, chronic kidney disease (CKD) is a major public health problem worldwide, and it causes tremendous socioeconomic burdens on the patients, families, and societies as well. ${ }^{[1]}$ Some causes of CKD include diabetes, hypertension, glomerulonephritis, cardiovascular disease etc. ${ }^{[2,3]} \mathrm{CKD}$ is also characterized as reduced glomerular filtration rate (GFR) but increased proteinuria, tubular atrophy, tubulointerstitial fibrosis, glomerulosclerosis, renal vasculopathy etc. ${ }^{[4,5]}$ Moreover, CKD is a progressive, irreversible disease, ${ }^{[6,7]}$ leading to permanent renal failure, which may require lifelong dialysis or kidney transplantation. ${ }^{[1,5]}$ Currently, the primary objective of treatment is to only slow down the disease progression, instead of curing it, and those patients have a high risk of death from stroke or heart attack as well. ${ }^{[3]}$ On the other hand, the incidence of CKD is steadily increasing and we need to have a better understanding of CKD to reduce or halt such an increasing incidence. There must be something in common and finding such a common factor could be a key to a better control of this progressive and incurable disease.

An increasing number of reports now suggest that oxidative stress (OXS), i.e. generation of reactive oxygen species (ROS), is prevalent in CKD patients and may play a substantial role in the incidence/development of CKD. ${ }^{[5-8]}$ A variety of ROS can create a state of OXS, capable of attacking, damaging, mutating, or even killing all kinds of cells including renal cells. It is thus plausible that OXS could ultimately lead to renal dysfunction, renal failure, or CKD.

If OXS were the primary basis of CKD, theoretically certain antioxidants should be able to effectively reduce the incidence of CKD. In fact, antioxidants have been shown to have beneficial or protective effects on cellular injury/damage caused by OXS. ${ }^{[9]} \mathrm{We}$ were particularly interested in the bioactive extract from Poria 
mushroom, PE. ${ }^{[10,11]}$ This is not just another mushroom but one of well-established medicinal mushrooms, which has been used in Traditional Chinese Medicine (TCM) for 2,000 years. ${ }^{[10]}$ It has been well characterized and found to have chemical constituents, such as triterpenes, polysaccharides, and steroids. ${ }^{[10]}$ In addition, PE has been shown to have various biological properties including antioxidant, renoprotective, anticancer, immunomodulatory, antiinflammatory, anti-hyperglycemic, antibacterial effects etc. ${ }^{[11-16]}$ Interestingly, it is possible that antioxidant and renoprotective activities of PE may help prevent CKD or even reduce its incidence. Moreover, PE has few side effects (documented in $\mathrm{TCM})$ as it is a natural agent, implying its potential therapeutic utility.

A rat model has been widely used for studying human CKD ${ }^{[17]}$ Adenine (ADN) given orally to rats will be metabolized to 2,8-dihydroxyadenine (2,8-DHA), which then precipitates and forms tubular crystals causing palpable kidney damage similar to human CKD. ${ }^{[17,18]}$ Such kidney damage could be extended (70$80 \%$ ) with fibrosis, enlarged granular appearance, apoptotic lesion etc. ${ }^{[19,20]}$ eventually leading to renal dysfunction with manifestation of CKD in rats. Hence, this is an appropriate experimental model for our study.

Accordingly, we first examined possible antioxidant activity of PE using cell culture in vitro. We then studied if PE might have prophylactic effect against $\mathrm{ADN}$-mediated CKD (via OXS) in rats. Furthermore, the adverse effects of ADN-induced OXS on the kidneys were also assessed from physiologic (renal function) and biochemical (injury biomarkers) prospects. More details of the study are described and the interesting findings are also discussed herein.

\section{Materials and Methods}

\subsection{Cell culture}

The renal tubular epithelial LLC-PK 1 cells (American Type Culture Collection, Manassas, VA) were employed as our in vitro experimental model. They were maintained in RPMI-1640 medium supplemented with $10 \%$ fetal bovine serum, penicillin (100 units/ml), and streptomycin $(100 \mu \mathrm{g} / \mathrm{ml})$ at $37{ }^{\circ} \mathrm{C}$ in a humidified incubator (with $95 \%$ air and $5 \% \mathrm{CO}_{2}$ ). For experiments, cells were seeded at the initial cell density of $\sim 2 \times 10^{5} \mathrm{cell} / \mathrm{ml}$ in the 6-well plates or T-75 flasks and treated with specified concentrations of hydrogen peroxide $\left(\mathrm{H}_{2} \mathrm{O}_{2}\right.$; Sigma-Aldrich, St. Louis, MO) and/or Poria mushroom extract (PE; Mushroom Wisdom, Inc., East Rutherford, NJ). After 24-h incubation, cells were subjected to cell viability test (MTT assay) as described below.

\subsection{Cell viability test (MTT assay)}

Cell viability was determined by MTT (3-[4,5-dimethylthiazol-2yl]-2,5-diphenyl-tetrazolium bromide) assay following the vendor's protocol (Sigma-Aldrich, St. Louis, MO). This will indicate what $\%$ of cells is yet viable under specific experimental conditions. MTT reagent $(1 \mathrm{mg} / \mathrm{ml})$ was added to the 6-well plate, which was incubated for $3 \mathrm{~h}$ at $37{ }^{\circ} \mathrm{C}$. After MTT was discarded, dimethyl sulfoxide (DMSO) was added to the plate and the absorbance of formazan solution (purple color) was read in a microplate reader. Cell viability was then expressed by the $\%$ of sample readings relative to the controls $(100 \%)$. All experiments were repeated three times separately to perform statistical analysis.

\subsection{Lipid peroxidation (LPO) assay}

The severity of oxidative stress (OXS) on LLC-PK 1 cells or the rat kidneys was assessed by LPO assay, measuring the amount of malondialdehyde (MDA) formed due to $\mathrm{OXS}^{[21]}$ - the more MDA formed, the greater OXS. The detailed procedures were described in the vendor's protocol (Abcam, Cambridge, MA). Briefly, the reaction was initiated by mixing cell extracts with thiobarbituric acid (TBA) solution and incubated in a boiling water bath $(\sim 100$ ${ }^{\circ} \mathrm{C}$ ) for $1 \mathrm{~h}$. Samples were read at $\mathrm{A}_{532}$ on a microplate reader, and the amount of MDA formed was calculated and expressed by foldincrease relative to control's (1). All experiments were repeated three times separately for performing statistical analysis.

\subsection{Animal study}

Whether PE would protect/prevent the rat kidneys from ADNmediated CKD was examined. CKD was chemically induced by orally giving the rats $\mathrm{ADN}(40 \mathrm{mg} / \mathrm{ml})$ daily for 2 weeks as described elsewhere. ${ }^{[8,11,22]}$ Twenty male Sprague-Dawley rats (200-250 g), fed with standard chow diet and free access to water, were randomly divided into 4 groups ( $\mathrm{n}=5$ per group): Sham group; $A D N$ group [Rats received $1 \mathrm{ml}$ of $\mathrm{ADN}$ (40 mg/ml) daily]; $A D N / P E$ group [Rats received $1 \mathrm{ml}$ each of ADN (40 mg/ml) and PE $(25 \mathrm{mg} / \mathrm{ml})$ daily]; and $P E$ group [Rats received only PE (25 $\mathrm{mg} / \mathrm{ml}$ ) daily]. At the end of 2 weeks, blood specimens were collected by retro-orbital bleeding and analyzed for blood urea nitrogen (BUN) and creatinine $(\mathrm{Cr})$, while kidney specimens were surgically excised and subjected to histopathologic examination and biochemical analyses.

\subsection{BUN/Cr tests and histopathologic examination}

Harvested blood and kidney specimens were sent to the commercial pathology laboratory for $\mathrm{BUN} / \mathrm{Cr}$ tests and histopathologic examination, respectively. Histopathologic examination was performed by two independent veterinary pathologists and the pathology reports were sent to us separately. The reports for BUN/Cr tests were also received separately.

\subsection{Western blot analysis}

Effects of OXS on three kidney injury biomarkers were analyzed using Western blots. Briefly, cell extracts $(10 \mu \mathrm{g})$, obtained from tissue homogenization, were subjected to SDS-polyacrylamide gel electrophoresis to resolve proteins and transferred to a nitrocellulose membrane. The blot (membrane) was incubated with primary antibodies against three biomarkers, neutrophil-gelatinaseassociated lipocalin (NGAL), kidney injury molecule 1 (Kim-1), and clusterin $(\mathrm{CLU})^{[23-25]}$ (Santa Cruz Biotechnology, Santa Cruz, CA) for $90 \mathrm{~min}$, followed by 30-min incubation with appropriate secondary antibody conjugates. Specific immunoreactive protein bands were detected by chemiluminescence following manufacturer's protocol (Kirkegaard and Perry Laboratories, Gaithersburg, MD).

\subsection{Statistical analysis}

All data are presented as mean \pm SD (standard deviation), and statistical differences between groups are assessed with the unpaired Student's $t$ test or one-way ANOVA analysis. Values of $\mathrm{p}$ $<0.05$ are considered statistically significant.

\section{Results}

\subsection{Cytotoxic effects of $\mathrm{H}_{2} \mathrm{O}_{2}$ but its prevention with $\mathrm{PE}$}

We examined if $\mathrm{H}_{2} \mathrm{O}_{2}$ would be cytotoxic to renal LLC-PK 1 cells but $\mathrm{PE}$ might protect cells from such cytotoxicity. How $\mathrm{H}_{2} \mathrm{O}_{2}$ would actually affect $\mathrm{LLC}-\mathrm{PK}_{1}$ cells in terms of cell viability was first examined. After cells were treated with $\mathrm{H}_{2} \mathrm{O}_{2}(0-100 \mu \mathrm{M})$ for $24 \mathrm{~h}$, cell viability was determined by MTT assay. The results showed that cell viability was significantly reduced to $\sim 25 \%$ as 
$\mathrm{H}_{2} \mathrm{O}_{2}$ concentrations went up to $100 \mu \mathrm{M}$ (Figure 1A). This demonstrates that $\mathrm{H}_{2} \mathrm{O}_{2}$ is indeed cytotoxic to LLC-PK $\mathrm{K}_{1}$ cells. Additionally, as the estimated $\mathrm{IC}_{50}$ value for $\mathrm{H}_{2} \mathrm{O}_{2}$ was approximately $70 \mu \mathrm{M}$, the rest of study was carried out using this concentration.

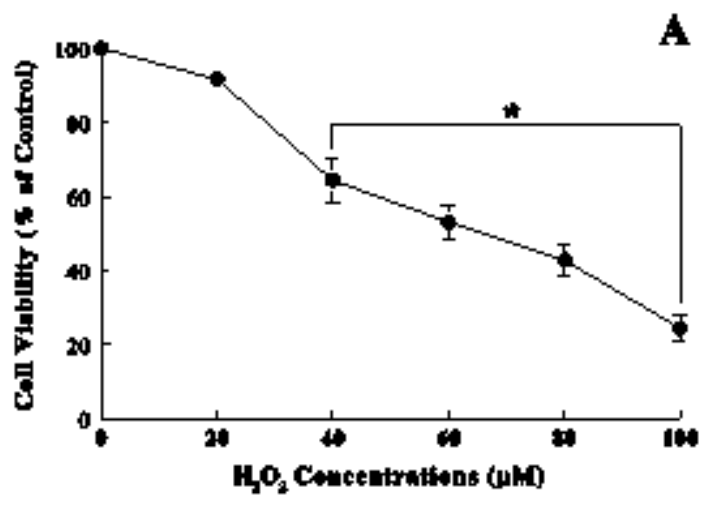

B

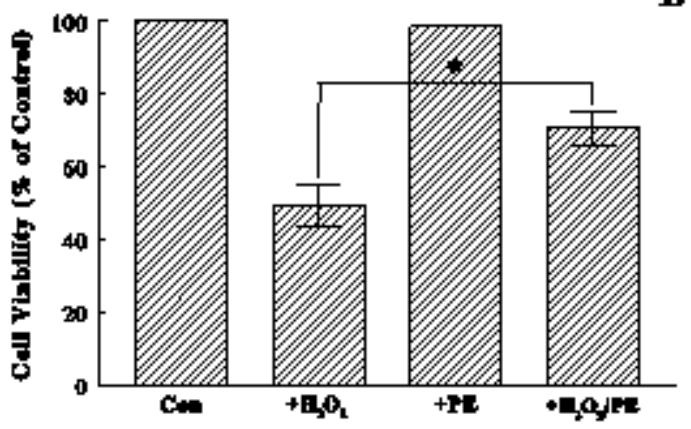

Figure 1: (A) Dose-dependent effects of $\mathrm{H}_{2} \mathrm{O}_{2}$ on LLC-PK 1 cell viability. After cells were exposed to varying concentrations of $\mathrm{H}_{2} \mathrm{O}_{2}(0-100 \mu \mathrm{M})$ for $24 \mathrm{~h}$, cell viability was determined by MTT assay. (B) Protective effect of PE against $\mathrm{H}_{2} \mathrm{O}_{2}$. Cells exposed to $\mathrm{H}_{2} \mathrm{O}_{2}(70 \mu \mathrm{M})$, PE $(50 \mu \mathrm{g} / \mathrm{ml})$, or their combination $\left(\mathrm{H}_{2} \mathrm{O}_{2} / \mathrm{PE}\right)$ for $24 \mathrm{~h}$ were assayed for cell viability. Cell viability is expressed by the $\%$ of sample readings relative to the controls (100\%). All data are mean $\pm \mathrm{SD}$ (standard deviation) from three separate experiments $(* \mathrm{p}<0.05)$.

We next examined if PE would protect LLC-PK 1 cells from $\mathrm{H}_{2} \mathrm{O}_{2}$ cytotoxicity, which could adversely affect cell viability. Cells were exposed to $\mathrm{H}_{2} \mathrm{O}_{2}(70 \mu \mathrm{M})$ alone, $\mathrm{PE}(50 \mu \mathrm{g} / \mathrm{ml})$ alone, or combination of $\mathrm{H}_{2} \mathrm{O}_{2}$ and PE for $24 \mathrm{~h}$. MTT assay showed that $\mathrm{H}_{2} \mathrm{O}_{2}$ led to a $\sim 50 \%$ reduction in cell viability, which improved to a $\sim 30 \%$ reduction (i.e. 20\% higher cell viability) with PE (Figure 1B). Thus, $\mathrm{PE}$ appears to effectively protect renal cells from $\mathrm{H}_{2} \mathrm{O}_{2}$ induced cytotoxicity, implying its renoprotective effect.

\subsection{Antioxidant activity of PE against OXS}

Now, the question is how $\mathrm{H}_{2} \mathrm{O}_{2}$ reduces cell viability or where its cytotoxicity comes from. As $\mathrm{H}_{2} \mathrm{O}_{2}$ is known to induce harmful oxidative stress (OXS), we tested such a possibility. Knowing that OXS usually takes place rapidly and abruptly, cells were exposed to $\mathrm{H}_{2} \mathrm{O}_{2}(70 \mu \mathrm{M})$ alone, $\mathrm{PE}(50 \mu \mathrm{g} / \mathrm{ml})$ alone, or $\mathrm{H}_{2} \mathrm{O}_{2} / \mathrm{PE}$ combination for merely $6 \mathrm{~h}$. The severity of OXS was assessed by LPO assay as described in Materials and Methods. Such results revealed that no apparent changes in the amount of MDA formed were seen in control or PE-exposed cells (Figure 2). However, $\mathrm{H}_{2} \mathrm{O}_{2}$ led to a $\sim 2$.6-fold increase (compared to controls) in the MDA amounts, which was yet significantly $(\sim 24 \%)$ reduced with $\mathrm{PE}$ (Figure 2). Therefore, $\mathrm{H}_{2} \mathrm{O}_{2}$ appears to exert severe OXS on
LLC-PK 1 cells, but PE is capable of effectively diminishing such oxidative assault, demonstrating its antioxidant activity.

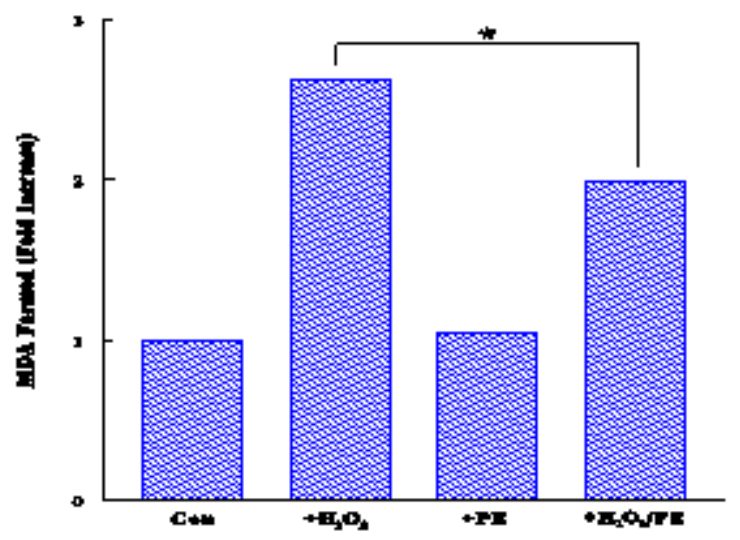

Figure 2: Severity of OXS. Cells were exposed to $\mathrm{H}_{2} \mathrm{O}_{2}(70 \mu \mathrm{M})$, PE $(50 \mu \mathrm{g} / \mathrm{ml})$ or their combination $\left(\mathrm{H}_{2} \mathrm{O}_{2} / \mathrm{PE}\right)$ for $6 \mathrm{~h}$ and $\mathrm{LPO}$ assay was performed to assess the severity of OXS. The amount of MDA formed was calculated (in triplicate) and expressed by foldincrease relative to controls ( 1 ). (*p $<0.05$ compared between two groups).

\subsection{Histopathologic examination on rat kidneys}

Since PE is capable of protecting LLC-PK 1 cells from OXS mediated through $\mathrm{H}_{2} \mathrm{O}_{2}$, we further investigated if $\mathrm{PE}$ might prevent $\mathrm{ADN}$-induced $\mathrm{CKD}$ in the rats, due to OXS. As described in Materials and Methods, 20 male rats were randomly divided into 4 groups: Sham group, $A D N$ group (Rats received ADN daily), $A D N / P E$ group (Rats received both $\mathrm{ADN}$ and PE daily), and $P E$ group (Rats received only PE daily). After 2 weeks, all rats were sacrificed and blood and kidney specimens were collected for further analysis/examination. Effects of $\mathrm{ADN}$ and/or PE on the rat kidneys were examined histopathologically and the findings are displayed in Figure 3. Briefly, the Sham group shows normal, undamaged kidneys while the ADN group exhibits palpable histological alterations with renal tubular degeneration, indicating typical kidney damage. However, such kidney damage is less notable with PE supplement in the ADN/PE group. As expected, histology of the PE group looks quite similar to that of the Sham group with an undamaged, normal appearance. Thus, PE is capable of protecting the kidneys from ADN assault to a certain extent, thereby preventing extended kidney damage (CKD).
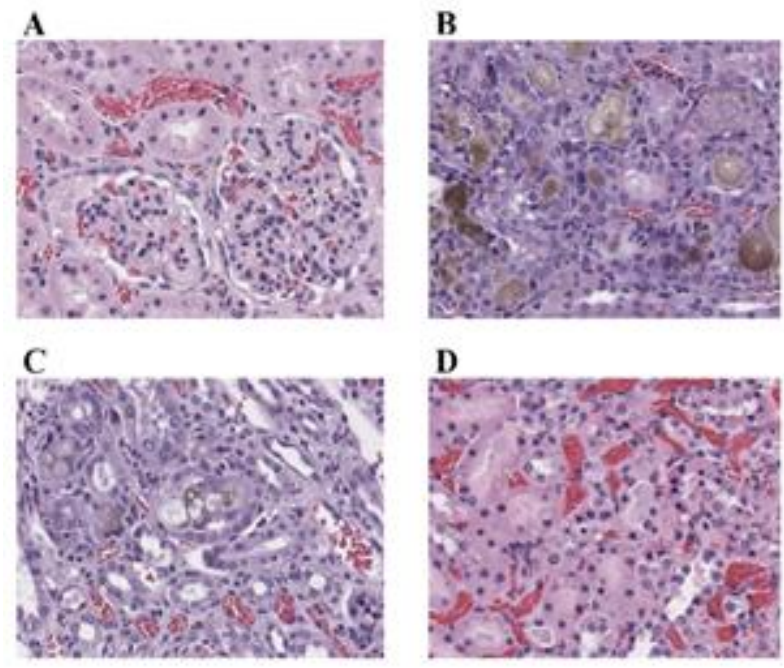

Figure 3: (A-D). Histopathology of kidney specimens (magnification, 400X). Kidney specimens of four experimental conditions were subjected to histopathologic examination. The 
results shown are: Sham group (A); ADN group (B); ADN/PE group (C); and PE group (D).

\subsection{ADN-induced OXS and PE}

To understand how ADN actually induces CKD, we hypothesized that $O X S$ (induced by $\mathrm{ADN}$ ) might play a key role and this possibility was tested next. The LPO assay was performed on rat specimens to determine the severity of OXS. As shown in Figure 4, ADN exerted $\sim 2.2$-fold greater OXS (on the kidneys) than the Sham group, but this elevated OXS level was significantly ( 27\%) reduced with $\mathrm{PE}$ supplement (ADN/PE group). As expected, PE alone had no effects (PE group). Thus, although ADN-mediated cytotoxicity appears to be primarily attributed to OXS, PE can yet significantly diminish/reduce it, demonstrating its antioxidant activity.

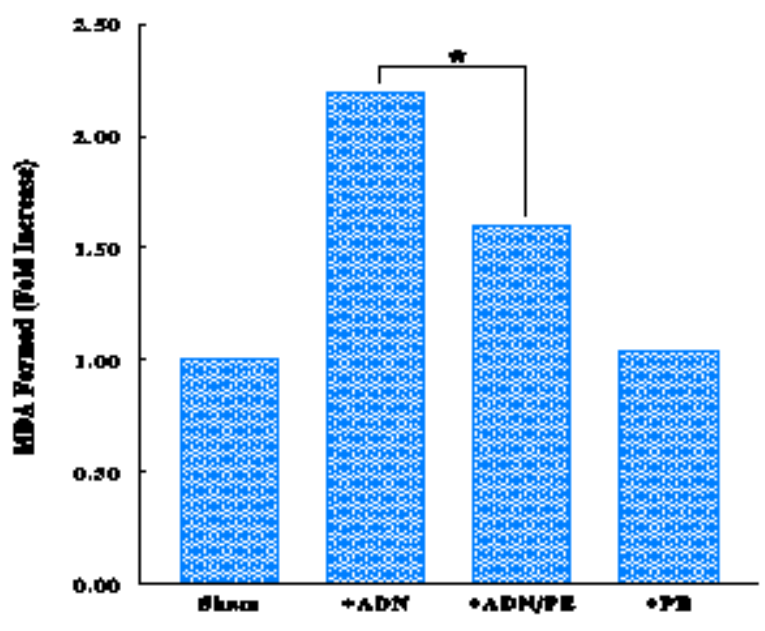

Figure 4: OXS mediated through ADN. The severity of OXS exerted on the rat kidneys was determined by LPO assay. The amount of MDA formed was calculated (in triplicate) and expressed by fold-increase relative to the Sham's (1). (*p $<0.05$ compared between two groups).

\subsection{ADN-induced OXS and PE}

To confirm if extended renal cell injury is linked to OXS, its effects on three kidney injury biomarkers, NGAL, Kim-1, and CLU in the rat kidneys were examined. Western blot analysis revealed that the expressions of all three biomarkers were enhanced or upregulated by $\mathrm{ADN}$, whereas these changes were yet prevented with $\mathrm{PE}$ (ADN/PE group) as they remained similar to those in the Sham's (Figure 5). It should be noted that the actual intensities of three biomarkers in the Sham and ADN/PE groups were quantitatively similar while those in the ADN group were significantly different from those in the Sham and ADN/PE groups, evidenced by densitometric analysis (data not shown). Thus, the up-regulation of these biomarkers is indicative of renal cell injury ${ }^{[23,24,26]}$ however, sustaining their natural/basal status with $\mathrm{PE}$ also suggests that renal cells are well protected (from ADN attack) with PE.

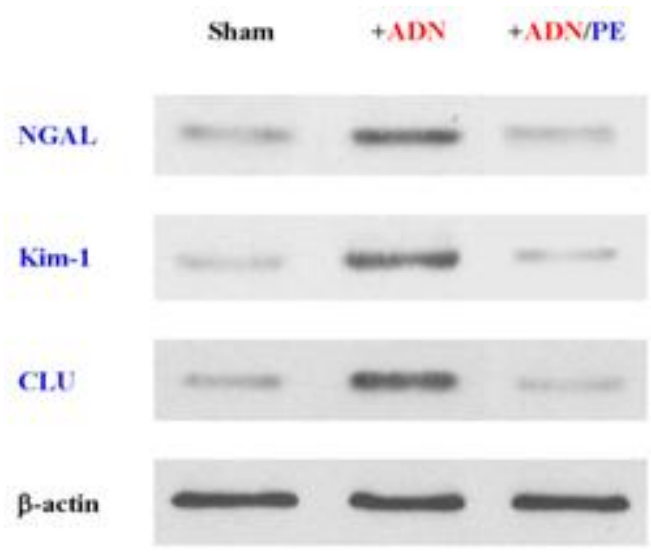

Figure 5: Up-regulation of kidney injury biomarkers by ADN. Kidney specimens obtained from different experimental conditions were analyzed for three biomarkers using Western blots. Autoradiographs of NGAL, Kim-1 and CLU are shown and $\square$ actin was also run as a protein loading control.

\subsection{Status of renal function following ADN and/or PE administration}

Lastly, as it was important to address the status of renal function following ADN or PE administration, all rats were subjected to the evaluation of BUN and creatinine ( $\mathrm{Cr}$ ) in blood specimens. Blood analysis (Table 1) showed that compared to the Sham group, the BUN and $\mathrm{Cr}$ levels were $\sim 3.8$ and $\sim 4.6$ times higher in the ADN group, respectively. However, these elevated BUN and Cr levels were reduced by $36-38 \%$ with $\mathrm{PE}$ supplement (ADN/PE group), while PE by itself had no such effects (PE group). Thus, the elevated $\mathrm{BUN} / \mathrm{Cr}$ levels by ADN indicate renal dysfunction, which seems to be significantly improved with PE supplement.

Table 1: Assessment of Renal Function

\begin{tabular}{|l|c|c|c|c|}
\hline $\begin{array}{l}\text { Experimental } \\
\text { Conditions }\end{array}$ & Sham & + ADN & + ADN/PE & + PE \\
\hline BUN & $17.6 \pm 2.1$ & $66.9 \pm$ & $43.1 \pm$ & $17.3 \pm$ \\
& & 4.6 & $3.3^{*}$ & 1.7 \\
\hline Creatinine & $0.47 \pm 0.1$ & $2.16 \pm$ & $1.34 \pm$ & $0.41 \pm$ \\
& & 0.13 & $0.1 *$ & 0.1 \\
\hline
\end{tabular}

\section{Discussion}

To better understand the primary cause of CKD, a progressive and incurable disease, we hypothesized that OXS could be such a key pathogenic factor and certain antioxidants might diminish or reduce it. In fact, antioxidants have been documented to effectively protect (renal) cells from such OXS. ${ }^{[9]} \mathrm{PE}$ has been shown to have various pharmacological properties including particularly antioxidant and renoprotective activities. ${ }^{[10,11]}$ Hence, we performed the in vivo study to address if PE might have protective effect against ADN to prevent or reduce the development of CKD mediated through OXS in a rat model.

First of all, our in vitro study showed that $\mathrm{H}_{2} \mathrm{O}_{2}$-induced cell viability reduction, due to OXS, was effectively prevented with $\mathrm{PE}$ (Figures 1 and 2), demonstrating renoprotective and antioxidant activities of PE. We then studied if PE would prevent or reduce the incidence of chemically-induced CKD in rats. ADN led to adverse histological changes with deposition of 2,8-DHA (brown pigmented crystals), tubular degeneration, interstitial mononuclear inflammation etc. in rat kidneys (Figure 3). These results thus suggest that accumulation of ADN crystals may trigger renal cell 
inflammation, tubular degeneration, renal dysfunction, and ultimately result in CKD.

Nevertheless, our next question was how ADN crystals would induce such severe renal cell damage. We then looked into possible OXS induced by ADN and found that OXS was indeed elevated to 2.2-fold higher/severer in the ADN group (than that in the Sham) (Figure 4). This finding suggests that ADN is capable of exerting severe OXS on renal cells, feasibly leading to renal cell injury and renal dysfunction. To confirm such OXS-induced renal cell injury, we also examined the status or expressions of three kidney injury biomarkers, NGAL, Kim-1, and CLU, ${ }^{[23-25]}$ in the rat kidneys. All biomarkers in the ADN group were up-regulated or expressed more intensely (compared to those in the Sham), indicating apparent renal cell injury. ${ }^{[23,24,26]}$ Particularly, as NGAL is a stable, small molecule ( $25 \mathrm{kDa})$ that is excreted and easily detected in urine, it has been validated as a useful biomarker for CKD progression. ${ }^{[27]}$ After all, these findings support the notion that ADN-induced OXS can lead to extended renal cell damage/injury, resulting in renal dysfunction and ultimate CKD. Despite severe ADN-induced renal injury through OXS, PE was capable of significantly diminishing OXS (Figure 4) and maintaining the basal status of all three biomarkers (under OXS) (Figure 5), demonstrating its antioxidant activity to protect renal cells from OXS.

After all, those histopathological alterations caused by ADN apparently led to renal dysfunction, indicated by the significantly increased levels of BUN and $\mathrm{Cr}$ (Table 1). However, such elevated BUN and Cr levels have declined with PE supplement, implying the improvement in renal function. Therefore, PE appears to physically and functionally protect the (rat) kidneys from ADNmediated OXS.

In addition, it would be interesting to talk more about antioxidant activity of PE. Today, many synthetic antioxidants are available in the market but they could be potentially hazardous to your health. ${ }^{[28]}$ In contrast, PE is considered as a natural antioxidant with few side effects and its safety has been well documented in TCM. A number of mushrooms (including Poria) have been shown to exhibit strong activity of scavenging ROS and considered as potential natural antioxidants. ${ }^{[29,30]}$ Strictly speaking, various derivatives (such as PE) of Poria mushroom have been isolated with the diverse degrees of biological properties such as antioxidant, anticancer, immunological activities etc. ${ }^{[31]}$ For instance, antioxidant activity of these derivatives could vary with others, but PE we used/tested appears to have fairly good antioxidant activity (reducing OXS by $\sim 30 \%$ ). It is yet possible that some other derivative(s) could have even better/stronger activity. This possibility may deserve further exploration.

Moreover, it would be worthwhile mentioning that the amount of ADN crystals formed/deposited in the rat kidneys appears to be significantly less with PE supplement. This suggests that PE could somehow interfere with the metabolic pathway of $\mathrm{ADN}$ to 2,8-DHA conversion. In general, as ADN is efficiently salvaged by adenine phosphoribosyltransferase, it is usually kept at the significantly low level in blood and urine ${ }^{[32]}$ However, once ADN becomes excessive, it acts as a substrate for xanthine dehydrogenase, which could then oxidize ADN to 2,8-DHA. ${ }^{[18]}$ Due to such a low solubility of 2,8-DHA, it readily precipitates in renal tubules and forms tubular crystals. ${ }^{[20]}$ Hence, it can be speculated that PE may disrupt the conversion of ADN to 2,8-DHA by inhibiting/inactivating xanthine dehydrogenase, although other unknown mechanisms cannot be ruled out. This deserves further investigations.
Taken together, chemically-induced CKD in the rats could be primarily attributed to severe OXS on renal cells. OXS can cause renal cell damage/injury and dysfunction, consequently resulting in $\mathrm{CKD}$. However, PE is capable of protecting the kidneys from all these adverse effects induced by OXS. This finding is also consistent with the early report describing that another isolated extract of Poria mushroom has been used for the prevention or treatment of CKD. ${ }^{[33]}$

\section{Conclusions}

The present study demonstrates that oxidative stress plays a key role in inducing chronic kidney disease in vitro and in vivo. However, the Poria mushroom extract with antioxidant activity has the preventative or prophylactic effect on the development of chronic kidney disease. Thus, this Poria mushroom extract could be a promising natural antioxidant against a progressive, incurable disease and may have clinical implications with few side effects. Further studies are certainly warranted.

\section{Ethics approval and consent to participate}

The protocol for our animal study has been reviewed and approved by the Institutional Animal Care and Use Committee (IACUC) at the College. The IACUC approval number is \#10-1-0216.

\section{List of abbreviations}

OXS: oxidative stress

CKD: chronic kidney disease

PE: Poria mushroom extract

ADN: adenine

2,8-DHA: 2, 8-dihydroxyadenine

$\mathrm{H}_{2} \mathrm{O}_{2}$ : hydrogen peroxide

GFR: glomerular filtration rate

ROS: reactive oxygen species

TCM: Traditional Chinese Medicine

MTT: 3- [4,5-dimethylthiazol-2-yl] -2,5-diphenyl-tetrazolium

bromide

DMSO: dimethyl sulfoxide

$\mathrm{IC}_{50}: 50 \%$ inhibitory concentration

LPO: lipid peroxidation

MDA: malondialdehyde

TBA: thiobarbituric acid

BUN: blood urea nitrogen

Cr: creatinine

NGAL: neutrophil-gelatinase-associated lipocalin

Kim-1: kidney injury molecule 1

CLU: clusterin

kDa: kilodaltons

SD: standard deviation

ANOVA: analysis of variance

\section{Data Availability}

The data described in this article will be available upon request and shared by signing the data access agreement. For further information, contact a corresponding author.

\section{Funding Statement}

A major financial support has been made by General Incorporated Association MAM (mamjp.org; Tokyo, Japan). 


\section{Authors' contributions}

JW performed all experiments and collected the data. $\mathrm{KZ}$ served as an essential assistant for JW. MC worked on administrative and financial matters. ME gave us his critical opinions and guidance. SK designed experiments, interpreted the data and primarily wrote this manuscript. All authors have read and approved the final manuscript.

\section{Conflicts of Interest}

The authors declare to have no conflict of interest.

\section{Acknowledgements}

We would like to thank MAM (mamjp.org) for their generous financial support in this study. We also thank Ms. Donna Noonan (President, Mushroom Wisdom, Inc.) for kindly providing us with $\mathrm{PE}$ and her devoted support.

\section{References}

[1] Liu Y: Cellular and molecular mechanisms of renal fibrosis. Nat Rev Nephrol 2011;7:684-696.

[2] Winearls CG: Chronic kidney disease: Definition and staging - An orthodox view. Clin Med (Lond) 2009;9:563-564.

[3] Jha V, Garcia-Garcia G, Iseki K, et al: Chronic kidney disease: Global dimension and perspectives. Lancet 2013;382:260-272.

[4] Lopez-Novoa JM, Rodriguez-Pena AB, Ortiz A, Martinez-Salgado C, Lopez Hernandez FJ: Etiopathology of chronic tubular, glomerular and renovascular nephropathies: clinical implications. J Transl Med 2011 doi: 10.1186/1479-5876-9-13.

[5] Small DM, Coombes JS, Bennett N, Johnson DW, Gobe GC: Oxidative stress, anti-oxidant therapies and chronic kidney disease. Nephrology (Carlton) 2012;17:311-321.

[6] Krata N, Zagozdzon R, Foroncewicz B, Mucha K: Oxidative stress in kidney diseases: the cause of the consequence? Arch Immunol Ther Exp (Warsz) 2018;66:211-220.

[7] Ali BH, Al-Husseni I, Beegam S, et al: Effect of gum arabic on oxidative stress and inflammation in adenineinduced chronic renal failure in rats. PLoS One 2013;8:e55242.

[8] Chang XY, Cui L, Wang XZ, et al: Quercetin attenuates vascular calcification through suppressed oxidative stress in adenine-induced chronic renal failure rats. Biomed Res Int 2017 https://doi.org/10.1155/2017/ 5716204.

[9] Cutler RG: Antioxidants and aging. Am J Clin Nutr 1991;53:373S-379S.

[10] Rios JL: Chemical constituents and pharmacological properties of Poria cocos. Planta Med 2011;77:681-691.

[11] Zhou L, Zhang Y, Gapter LA, et al: Cytotoxic and antioxidant activities of lanostane-type triterpenes isolated from Poria cocos. Chem Pharm Bull (Tokyo) 2008;56:1459-1462.

[12] Zhao YY, Lei P, Chen DQ, Feng YL, Bai X: Renal metabolic profiling of early renal injury and renoprotective effects of Poria cocos epidermis using UPLC Q-TOF/HSMS/MS ${ }^{\mathrm{E}}$. J Pharm Biomed Anal 2013;81-82:202-209.
[13] Chen X, Zhang L, Cheung PC: Immunopotentiation and anti-tumor activity of carboxymethylated-sulfated $\beta$ $(1 \rightarrow 3)$-D-glucan from Poria cocos. Int Immunopharmacol 2010;10:398-405.

[14] Fuchs SM, Heinemann C, Schliemann-Willers S, et al: Assessment of anti-inflammatory activity of Poria cocos in sodium lauryl sulphate-induced irritant contact dermatitis. Skin Res Technol 2006;12:223-227.

[15] Li TH, Hou CC, Chang CLT, Yang WC: Antihyperglycemic properties of crude extract and triterpenes from Poria cocos. Evid Based Complement Alternat Med 2011;10:1-8.

[16] Zhang L, Ravipati AS, Koyyalamudi SR, et al: Antifungal and anti-bacterial activities of ethanol extracts of selected traditional Chinese medicinal herbs. Asian Pac J Trop Med 2013;6:673-681.

[17] Diwan Y, Mistry A, Gobe G, Brown L: Adenine-induced chronic kidney and cardiovascular damage in rats. J Pharmacol Toxicol Methods 2013;68:197-207.

[18] Koeda T, Wakaki K, Koizumi F, Yokozawa T, Oura H: Early changes of proximal tubules in the kidney of adenine-ingesting rats, with special reference to biochemical and electron microscopic studies. Nihon Jinzo Gakkai Shi 1988;30:239-246.

[19] Shuvy M, Nyska A, Beeri R, et al: Histopathology and apoptosis in an animal model of reversible renal injury. Exp Toxicol Pathol 2011;63:303-306.

[20] Yokozawa T, Zheng PD, Oura H, Koizumi F: (1988) Animal model of adenine-induced chronic renal failure in rats. Nephron 1988;44:230-234.

[21] Dargel R: Lipid peroxidation: a common pathogenetic mechanism? Exp Toxicol Pathol 1992;44:169-181.

[22] Ali BH, Al-Salam S, Al Za'abi M, et al: New model for adenine-induced chronic renal failure in mice, and the effect of gum acacia treatment thereon: comparison with rats. J Pharmacol Toxicol Methods 2013;68:384-393.

[23] Charlton JR, Portilla D, Okusa MD: A basic science view of acute kidney injury biomarkers. Nephrol Dial Transplant 2014;29:1301-1311.

[24] Wunnapuk K, Liu X, Peake P, et al: Renal biomarkers predict nephrotoxicity after paraquat. Toxicol Lett 2013;222:280-288.

[25] Satirapoj B, Nast CC, Adler SG: Novel insights into the relationship between glomerular pathology and progressive kidney disease. Adv Chronic Kidney Dis 2012;19:93-100.

[26] Nemmar A, Karaca T, Beegam S, et al: Lung oxidative stress, DNA damage, apoptosis, and fibrosis in adenineinduced chronic kidney disease in mice. Front Physiol 2017 https://doi.org/10.3389/fphys.2017.00896.

[27] Malyszko J, Bachorzewska-Gajewska H, Sitniewska E, et al: Serum neutrophil gelatinase-associated lipocalin as a marker of renal function in non-diabetic patients with stage 2-4 chronic kidney disease. Ren Fail 2008;30:625628.

[28] Aug A, Altraja A, Altraja S, et al: Alterations of bronchial epithelial metabolome by cigarette smoke are reversible by an antioxidant, O-methyl-L-tyrosinyl- $\gamma$-Lglutamyl-L-cysteinylglycine. Am J Respir Cell Mol Biol 2014;51:586-594.

[29] Wei XJ, Hu TJ, Chen JR, Wei YY: Inhibitory effect of carboxymethylpachymaran on cyclophosphamide- 
induced oxidative stress in mice. Int $\mathrm{J}$ Biol Macromol 2011;49:801-805.

[30] Cor D, Knez Z, Hrncic MK: Antitumor, antimicrobial, antioxidant and antiacetylcholinesterase effect of Ganoderma lucidum terpenoids and polysaccharides: A review. Cor D, Knez Z, Hrncic MK (2018) Antitumor, antimicrobial, antioxidant and antiacetylcholinesterase effect of Ganoderma lucidum terpenoids and polysaccharides: A review. Molecules 23: 649 https:// doi.org/10.3390/molecules23030649.

[31] Wei YY, Hu TJ, Su ZJ, Wei XJ, Zhang SX: Immunomodulatory and antioxidant effects of carboxymethylpachymaran on the mice infected with PCV2. Int J Biol Macromol 2012;50:713-719.

[32] Engle SJ, Stockelman MG, Chen J, et al: Adenine phosphoribosyltransferase-deficient mice develp 2,8dihydroxyadenine nephrolithiasis. Proc Natl Acad Sci USA 1996;93:5307-5312.

[33] Zhao YY, Li HT, Feng YL, Bai X, Lin RC: Urinary metabonomic study of the surface layer of Poria cocos as an effective treatment for chronic renal injury in rats. $\mathrm{J}$ Ethnopharmacol 2013;148:403-410. 